\title{
FÓRUM DE DISCUSSÃO COMO FERRAMENTA NO ENSINO DE ADMINISTRAÇÃO: UM ESTUDO EM UMA DISCIPLINA DE ESTATISTICA APLICADA
}

\author{
ASYNCHRONOUS FORUM DISCUSSION AS A TOOL \\ ON THE TEACHING OF BUSINESS: A STUDY ON A \\ STATISTICS APPLIED TO BUSINESS DISCIPLINE
}

\author{
Data de submissão: 21-01-2013 \\ Aceite: $17-05-2014$ \\ Daielly Melina Nassif Mantovani ${ }^{1}$ \\ Maria Aparecida Gouvêa ${ }^{2}$ \\ Adriana Backx Noronha Viana ${ }^{3}$
}

\section{RESUMO}

O objetivo deste artigo é avaliar a aplicação da ferramenta fórum no ensino de Estatística Aplicada à Administração. Para tanto, realizou-se um estudo de caso único, com tratamento descritivo dos dados, que focalizou uma interação via fórum, realizada durante uma disciplina semipresencial, com a finalidade de aproximar conceitos teóricos e o uso da estatística no contexto de negócios. Esta interação consistiu do debate sobre um artigo acadêmico que utilizou a técnica ANOVA para análise de dados. Observou-se que a maior parte das mensagens postadas foi considerada correta e relevante e caracterizavam discussão em profundidade. No entanto, houve grande repetição, pico de postagens no último dia do fórum e poucos acessos após seu encerramento como fonte de consulta. Observou-se que os alunos do período diurno tiveram participação mais adequada do que os alunos do período noturno, postando maior quantidade de mensagens novas e profundas. O fórum pode ser utilizado na educação, porém é necessário que haja planejamento prévio, antecipando-se a possíveis problemas e elaborando-se ações para corrigi-los.

Palavras-chave: Educação a Distância. Ensino de Estatística Aplicada à Administração. Fórum.

\footnotetext{
1 Possui graduação em Administração pela Universidade de São Paulo, USP, mestrado em Administração pela Universidade de São Paulo, USP e doutorado em Administração pela Universidade de São Paulo, USP. São Paulo. São Paulo. Brasil. E-mail: daimantovani@gmail.com 2 Possui graduação em Bacharelado em Estatística pela Universidade de São Paulo, USP, graduação em Bacharelado em Letras pela Universidade de São Paulo, USP, mestrado em Estatística pela Universidade de São Paulo, USP e doutorado em Administração pela Universidade de São Paulo, USP. São Paulo. São Paulo. E-mail: magouvea@usp.br

3 Possui graduação em Matemática - Licenciatura pela Universidade de São Paulo, USP, mestrado em Ciências da Computação e Matemática Computacional pela Universidade de São Paulo, USP e doutorado Engenharia Elétrica pela Universidade Estadual de Campinas, UNICAMP. São Paulo. São Paulo. Brasil. E-mail: backx@usp.br
} 


\begin{abstract}
This article aims to assess the use of forum tool on the teaching of Statistics Applied to Administration. For this purpose, a case study has been done, with descriptive treatment of data, which focused on an interaction through a forum, occurred on a blended discipline. The forum intended to bring the Statistic's theoretical concepts and the real use of them on business field. That interaction consisted of discussion of scientific paper which had used the Analysis of Variance (ANOVA) on its data analysis. Most of the messages posted by the students were considered correct and relevant, defining a deep discussion. However, there was a high level of repetition, many messages were posted on the last day of the activity and the forum was lowly accessed after its conclusion as a research source. We've observed that daytime students participated more adequately than nocturnal students, posting a higher quantity of new and deep messages. Forum discussion tool can be used in education, but it needs a previous planning and anticipation of possible problems, developing actions to correct them.
\end{abstract}

Keywords: Distance Education. Teaching of Statistics Applied to Administration. Forum.

\title{
1 INTRODUÇÃO
}

A disciplina de Estatística é inserida nos cursos de graduação com objetivo de desenvolver a capacidade de análise crítica de dados estatísticos básicos que venham a ser encontrados em contextos diversos, como situações profissionais ou mesmo em artigos de jornal (NOLAN; SPEED, 1999; GOULD, 2010). Gould (2010) destaca que esta disciplina deve ser ensinada nos cursos de graduação com objetivo de formar bons cidadãos e bons profissionais. Nessa perspectiva, a Estatística deixa de ser um conjunto de conhecimentos úteis apenas para alguns grupos específicos de profissionais e passa a ter aplicações também em ciências sociais, negócios, medicina, biologia, meteorologia entre outras áreas do saber (GOULD, 2010).

Todavia, embora a relevância dos conhecimentos estatísticos fosse reconhecida em diversas áreas, o ensino dessa disciplina enfrentou desafios e insucessos. Para Gould (2010) embora o objetivo fosse formar cidadãos e profissionais qualificados a raciocinar e manipular dados, o ensino de estatística tornou-se enfadonho e tedioso ao estudante, ao utilizar situações de aprendizagem ideais ao invés de aplicar os conceitos estatísticos na solução de problemas reais. Consequentemente, é comum encontrar alunos com altas notas na disciplina de Estatística, que sejam excelentes em aplicações de fórmulas; porém, que não consigam explicar conceitos básicos como, por exemplo, média e desvio-padrão (GOULD, 2010).

O curso de Administração exige diferentes habilidades pessoais e profissionais, o que gera a necessidade de transformar o processo educacional em algo mais dinâmico e voltado ao campo de atuação do administrador, ou seja, os conteúdos de todas as disciplinas, inclusive a Estatística, devem ser articulados ao contexto de ação profissional (CORDEIRO; SILVA, 2012). Giuliani (2010) argumenta ainda que a universidade deve apresentar um espaço privilegiado para estimular discussões entre indivíduos que representam o tecido social. Além disso, a qualificação profissional desenvolvida no ensino superior deve ser uma resposta às exigências do mercado e da sociedade (GIULIANI, 2010), o que corrobora com a necessidade de se privilegiar o ensino voltado para o contexto prático. No caso do profissional de Administração, a acirrada competitividade dos mercados em que atuam grande parte das organizações, força de maneira veemente o desenvolvimento de novas habilidades e competências aos profissionais, para que se alcancem vantagens competitivas sustentáveis (VARGAS et al., 2012).

A Associação Americana de Estatística (American Statistical Association) criou, em 2005, algumas diretrizes para minimizar esse problema no ensino moderno de Estatística em cursos de 
graduação, dentre as quais, destacam-se: 1) focalizar o desenvolvimento de raciocínio estatístico crítico e literacia estatística; 2) usar dados reais; 3 ) focalizar a compreensão plena dos conceitos e não a memorização de fórmulas e procedimentos; 4 ) incentivar a aprendizagem ativa em sala de aula; 5) usar tecnologia para analisar os dados e para facilitar a compreensão dos conceitos; e, 6) criar formas de avaliação coerentes com os objetivos do curso, de forma a melhorar a aprendizagem do aluno, (ZIEFFLER et al., 2012). Estas diretrizes têm como objetivo tornar o ensino da Estatística para não estatístico, mais estimulante e autêntico (ZIEFFLER et al., 2012).

$O$ ensino de Estatística moderno é inseparável da tecnologia. Por exemplo, grandes volumes de dados só podem ser manipulados e interpretados com a ajuda de softwares (GOULD, 2010). Além disso, teconologias educacionais, especialmente $e$-learning, também têm sido empregadas para modificar a forma de se ensinar e aprender estatística (PAN, 2003). Isto implica, ao instrutor, pensar sob um ponto de vista distinto as formas como os conteúdos devem ser ensinados e comunicados em um ambiente não presencial (NIESS; GILLOW-WILES, 2013).

As ferramentas da educação a distância, no formato semipresencial, têm sido utilizadas no ensino superior de Estatística, com objetivo de flexibilizar o processo educacional e acomodar as diferenças individuais de aprendizagem (TEMPELAAR et al., 2010). Os pilares da educação a distância, propostos por Keegan (1996), enfatizam a interação entre instrutor/aluno e entre alunos, em uma dinâmica de mão-dupla, com a mediação de diferentes mídias (KEEGAN, 1996). Moore e Kearsley (2008) apontam a comunicação como fator crítico de sucesso para um curso mediado por tecnologia. Volery (2001) aponta que o engajamento, participação e autonomia do estudante também são fundamentais para o sucesso de um curso na modalidade a distância (VOLERY, 2001).

A ferramenta fórum é utilizada em educação a distância com objetivo de promover discussão e interação entre instrutor e alunos e entre os alunos. Embora a interação seja reconhecida como fundamental para esta modalidade de cursos, a promoção da comunicação nos ambientes não presenciais é complexa (LAAT; LALLY, 2004), suscitando o seguinte problema de pesquisa:

- Qual a efetividade da interação via fórum de discussão na condução de uma disciplina técnica no curso de Administração?

Assim, o artigo pretende investigar se a interação efetivamente pode ocorrer no ambiente online por meio de fórum de discussão voltado para o ensino de Estatística Aplicada à Administração.

Realizou-se uma pesquisa descritiva e exploratória, por meio da estratégia do estudo de caso único, com o objetivo de analisar a utilização da ferramenta fórum no ensino de Estatística Aplicada à Administração. Nesse sentido, abordou-se uma interação com objetivo educacional via fórum de discussão, realizada em uma disciplina semipresencial de Estatística da Faculdade de Economia, Administração e Contabilidade de Ribeirão Preto (FEA-RP/USP). As mensagens trocadas nesse fórum foram avaliadas por meio de análise de conteúdo, que avaliou os tipos de mensagens mais frequentes e sua relevância, adequação e qualidade. Examinaram-se também os padrões de horários em que as mensagens foram postadas e, pela análise de correspondência, buscou-se relacionar os períodos do curso (diurno e noturno) ao desempenho do aluno na atividade fórum.

Desta forma, o artigo busca trazer insights sobre como se utilizar de tecnologias educacionais no ensino de Estatística para a área de negócios, assim como promover uma abordagem de ensino voltada à prática; isto é, aproximar a teoria estatística ao seu uso nas empresas. 


\section{REVISÃO DA LITERATURA}

Este capítulo apresenta a fundamentação teórica do estudo. Inicialmente, discutem-se as características da comunicação online. A seguir, apresenta-se o fórum como ferramenta de apoio ao processo de ensino-aprendizagem. Por fim, são apresentados casos empíricos encontrados na literatura que aplicaram a ferramenta fórum em experiências de ensino-aprendizagem.

\subsection{Comunicação online}

O processo de interação ou comunicação é uma dimensão essencial para a efetividade do ensino-aprendizagem (GARRISON; CLEVELAND-INNES, 2005; FREITAS; BERTRAND, 2006). Assim, a aprendizagem ocorre pela participação regular em discussões e debates, seja em ambientes presenciais ou não presenciais, o que indica que a comunicação é condição necessária para que os objetivos de aprendizagem sejam atendidos, bem como a motivação e a satisfação do discente seja alcançada (MABRITO, 2006; ANDRESEN, 2009).

Durante a interação, o conhecimento construído de maneira compartilhada pelos membros do grupo de discussão é significativamente maior do que a soma dos conhecimentos individuais, caso o participante estudasse os tópicos discutidos individualmente. Assim, o conhecimento individual é expandido, devido às discussões e à expressão de ideias (NIESS; GILLOW-WILES, 2013).

A evolução das tecnologias, com a criação de computadores mais velozes e redes de telecomunicação mais avançadas impulsionaram a expansão da educação a distância no mundo todo (ANDRESEN, 2009). Embora a comunicação seja importante no processo educacional de maneira geral, quando se trata de educação a distância, sua importância recebe ainda maior ênfase; pois, nesse novo contexto educacional, aluno e instrutor podem estar separados temporalmente e geograficamente, o que, por vezes leva à sensação de isolamento (MOORE; KEARSLEY, 2008). Os momentos de interação planejados e orientados levam o aluno a assumir um papel ativo e engajado no processo, atingindo-se os objetivos didáticos de desenvolvimento do pensamento crítico e reflexivo (GARRISON; CLEVELAND-INNES, 2005; BEUCHOT; BULLEN, 2005).

A comunicação não presencial pode ocorrer de forma síncrona (tempo real) ou assíncrona; porém, devido à distância, é necessário desenvolver novas formas de se expressarem emoções e de se motivarem os estudantes, já que elementos como tom de voz e linguagem corporal são perdidos em especial nos encontros assíncronos (ANDRESEN, 2009). Exemplos de ferramentas de comunicação síncrona são os vídeos e áudio-conferências e chat. Já as ferramentas assíncronas podem ser fórum, blogs, wikis, entre outras. Para Murphy et al. (2011) a comunicação síncrona estimula a participação pessoal (relações sociais; intercâmbio de informações de forma menos estruturada; maior motivação dada pela possibilidade de feedback em tempo real), enquanto a comunicação assíncrona motiva a participação cognitiva (reflexão e construção dos inputs com antecedência à interação).

A discussão assíncrona, objeto deste estudo, é considerada um elemento-chave para que haja de fato geração de conhecimento no ambiente online (ANDRESEN, 2009). Entretanto, a personalidade e outras características pessoais, assim como elementos do ambiente social, que não estão sob o controle do instrutor, influenciam no desempenho educacional da comunicação online, uma vez que, apenas fazer uso de uma tecnologia de comunicação e lançar uma questão para debate não são suficientes para que se desenvolvam sinergias e engajamento cognitivo (LAAT; LALLY, 2004; ANDRESEN, 2009). 
Neste contexto, pode-se verificar que os momentos assíncronos dependem mais do planejamento pedagógico da interação do que da tecnologia em si, ou seja, a qualidade do design da atividade assíncrona tem maior influência do que as características da mídia empregada (MURPHY et al., 2011). Logo, torna-se oportuno avaliar a aplicação da ferramenta fórum no ensino de Estatística Aplicada à Administração, temática que estimula a realização deste estudo.

\subsection{Fórum de discussão como ferramenta de ensino}

O uso do fórum como sistema de comunicação em cursos não presenciais não é recente. Kear et al. (2010) destacam que a utilização do fórum pode trazer grandes benefícios que estimulam a adoção dessa ferramenta no ambiente de ensino. $O$ fórum estimula os alunos a se sentirem mais confortáveis postando perguntas, do que as fazendo em sala de aula tradicional; o fórum facilita a auto-expressão e a reflexão; o tempo para refletir resulta em contribuições de maior qualidade; as interações profundas contribuem para o desenvolvimento de uma comunidade entre alunos; o fórum estabelece uma relação mais próxima entre alunos e instrutores do que no ambiente tradicional de ensino; além de alunos tímidos conseguirem se pronunciar de forma mais conveniente (KEAR et al., 2010). Yang, Newby e Bill (2005) destacam as discussões em fórum com um recurso favorável à experimentação, exploração e mesmo prova das próprias ideias e formas de pensamento.

Por outro lado, pontos negativos também permeiam as interações via fórum. Segundo Kear et al. (2010), o fórum também pode causar desconforto dos alunos em engajarem-se em um debate com outros estudantes que não conhecem; sentimento de impessoalidade; maior exigência de tempo para esta atividade do que se levaria em uma interação tradicional; e dificuldade em acompanhar o desenvolvimento da discussão, em especial quando o tema é complexo e há muitos participantes.

Alavi e Taghizadeh (2013) afirmam que o fórum deve incentivar a presença cognitiva, ou seja, o quanto um aprendiz é capaz de construir significado por meio de reflexão e debate. Em geral, a presença cognitiva pode ocorrer em diferentes níveis, como: identificação de problemas para futura dicussão; exploração, em que os estudantes exploram uma ideia ou problema em discussão e debate; integração, onde se constrói significado após a exploração; resolução, onde o conhecimento compartilhado passa a ser aplicado a contextos práticos de resolução de problemas. Os autores ainda destacam que o grande desafio das discussões assíncronas é ultrapassar o nível da exploração (ALAVI; TAGHIZADEH, 2013).

De qualquer forma, as discussões em fórum representam um papel importante ao estimular a aprendizagem colaborativa, permitindo ampla comunicação entre os estudantes, para que possam fazer perguntas, articular seus pensamentos, explicar e justificar suas opiniões e compartilhar ideias (LI; DONG; HUANG, 2009), fomentando a autonomia e a criação de códigos próprios de comunicação e relacionamento social. Assim sendo, o fórum estimula a análise crítica e a reflexão sobre ideias e objetos estudados, utilizando como meio a escrita (YUSELTURK, 2010).

Neste contexto, considerando-se que a universidade deve apresentar um espaço privilegiado para estimular discussões entre indivíduos (GIULIANI, 2010), que o ensino de estatística deve ser articulado ao contexto de ação do profissional (CORDEIRO; SILVA, 2012) e que a ferramenta fórum pode promover a discussão no ambiente de ensino, torna-se oportuno investigar se a interação efetivamente pode ocorrer no ambiente online por meio de fórum de discussão voltado para o ensino de Estatística Aplicada à Administração. Espera-se que nos cursos de administração, a inserção de tais recursos possa estimular a aprendizagem dos acadêmicos deste curso. 


\subsection{Estudos empíricos sobre o uso do fórum de discussão como ferramenta de ensino}

Tendo em vista a atualidade da temática para o contexto do ensino, diversos autores tem procurado investigar as relações que permeiam a utilização do fórum como uma ferramenta de ensino (BATISTA; GOBARA, 2007; YUSELTURK, 2010; BALAJI; CHAKRABARTI, 2010).

Buscando detectar pontos positivos e negativos no uso da ferramenta fórum, Batista e Gobara (2007) investigaram um fórum conduzido em um curso de pós-graduação, totalizando 53 alunos e dez instrutores. Observaram que os professores, em geral, não tinham experiência prévia ou especialização para atuar com educação a distância, o que lhes acarretou dificuldades em conduzir interações nessa ferramenta. Sob a perspectiva dos alunos, $75 \%$ deles considerou que as interações no fórum contribuíram para estreitar a comunicação instrutor/aluno. Adicionalmente, verificou que os problemas enfrentados pelos estudantes foram atribuídos a falhas de moderação dos instrutores, o que reforça a necessidade do planejamento estruturado dessas atividades instrucionais (BATISTA; GOBARA, 2007).

Em sua pesquisa com 196 alunos de um programa online na Turquia, Yuselturk (2010) observou três grupos distintos de alunos nos fóruns, sendo eles: ativos (aqueles que postaram cinco ou mais mensagens), moderados (aqueles que postaram quatro mensagens ou menos) e inativos (que não postaram nenhuma mensagem). Cada um dos três grupos apresentou proporções próximas de alunos, isto é, um terço dos estudantes não participou das interações no fórum e apenas um terço participou das interações de forma ativa. Dentre as razões para a baixa participação, o autor destaca a dificuldade do aluno em administrar seu tempo; o grande investimento de tempo e esforço para ter uma contribuição apropriada no fórum; o fato de os alunos não conseguirem identificar tópicos sobre os quais pudessem debater; a complexidade dos temas propostos; e a dificuldade em interagir com pessoas desconhecidas (YUSELTURK, 2010).

Os autores Balaji e Chakrabarti (2010), por sua vez, investigaram possíveis relações entre a participação do aluno de um curso online em sessões de fórum e aspectos deste método de aprendizagem. O estudo de Balaji e Chakrabarti (2010) realizado em um curso de MBA de uma instituição de ensino privada na Índia considerou quatro sessões de fórum que tiveram como tema tópicos retirados de discussões em sala tradicional e de textos recomendados para leitura. Um total de 227 alunos participou e o desempenho da atividade foi medido pelo conteúdo da mensagem, participação, expressão e contribuição. O instrutor limitou-se a intermediar o debate e responder questionamentos que os próprios alunos não foram capazes de responder. Os autores observaram que o desempenho do instrutor (mantendo interesse e participação do aluno) na moderação do debate influencia fortemente a participação do aluno. O fato de a participação no fórum ter contado para a avaliação do aluno no curso também influenciou o nível de participação. Finalmente, o engajamento no fórum criou o senso de comunidade entre os alunos e laços sociais. Neste caso, a flexibilidade temporal, que permite ao aluno realizar as atividades em seu próprio ritmo não apresentou influência significante sobre o nível de participação, mas sim as notas atribuídas pela contribuição postada (BALAJI; CHAKRABARTI, 2010).

De maneira geral pode-se verificar a partir dos achados destes estudos que as interações online por via fórum não ocorrem de forma natural, isto é, o planejamento dos momentos de discussão e a intervenção do tutor na motivação do aluno, em correções e provocações são fundamentais. Desta forma, os estudos sugerem que o êxito do fórum de discussão como ferramenta no processo de ensino-aprendizagem, requer um planejamento detalhado da atividade, desde a escolha do tópico de discussão, o treinamento do tutor, a elaboração das intervenções, até a correção, feedback e avaliação do desempenho do aluno. 
O estudo proposto difere-se das pesquisas anteriores ao tratar da utilização da ferramenta fórum em um curso de graduação semipresencial na área de negócios, focalizando uma disciplina da área de exatas, tida como complexa e desafiadora por ambos, alunos e professores. Adicionalmente, dadas as dificuldades e limitações apresentadas nos estudos revisados, o planejamento da atividade fórum e, em especial, o treinamento da tutoria foram realizados de forma a reduzir os problemas enfrentados por outros pesquisadores. Neste contexto, os conceitos e estudos apresentados nessa revisão da literatura consistiram nas principais diretrizes que nortearam a realização da pesquisa sobre a ferramenta fórum focalizada neste trabalho.

\section{METODOLOGIA}

\subsection{Descrição da pesquisa}

A pesquisa, cujo objetivo geral foi definido como: "analisar a utilização da ferramenta fórum no ensino de Estatística Aplicada à Administração", pode ser classificada como um estudo descritivo, exploratório, realizado por meio da estratégia do estudo de caso. Segundo Gil (2002), a pesquisa descritiva propõe-se a descrever características do fenômeno de interesse ou encontrar relações entre variáveis. Os estudos exploratórios, de acordo com Gil (2002, p. 41), "têm como objetivo proporcionar maior familiaridade com o problema, com vistas a torná-lo mais explícito ou a construir hipóteses". Essas pesquisas buscam lapidar as ideias e explorar intuições. Dado o problema que norteou a pesquisa, uma abordagem descritiva e exploratória mostrou-se adequada, para ampliar os conhecimentos acerca do uso da discussão assíncrona via fórum, para o ensino de Estatística no curso de Administração.

Como se estudou um caso específico, isto é, um fórum de debate conduzido em uma disciplina de graduação do curso de Administração, a estratégia de pesquisa foi o estudo de caso único. Segundo Yin (2005, p.32), um estudo de caso é "uma investigação empírica que analisa um fenômeno contemporâneo dentro de seu contexto real, quando os limites entre o fenômeno e o contexto não estão claramente definidos", e o pesquisador não possui controle sobre os eventos comportamentais, de forma que a coleta e análise de dados apresentam características específicas. Os estudos de caso são utilizados com o objetivo de aumentar a compreensão acerca de fenômenos sociais complexos e de responder a perguntas do gênero "como?" e "por quê?", permitindo-se preservar os aspectos significativos dos acontecimentos reais (YIN, 2005).

\subsection{Proposições do estudo}

A partir da revisão da literatura elaborada para a realização deste estudo, foi possível o estabelecimento das seguintes proposições teóricas:

- P1: Há predominância de mensagens que caracterizam discussões aprofundadas (debates) (baseado em MABRITO, 2006);

- P2: As mensagens são predominantemente relevantes ao assunto discutido (baseado em YANG, NEWBY; BILL, 2005);

- P3: As mensagens, em maioria, apresentam ideias novas que não haviam sido anteriormente expostas na discussão;

- P4: As mensagens, em maioria, são consideradas corretas em termos teóricos;

- P5: Há participação da maioria dos alunos, devido à obrigatoriedade da atividade (baseado em YUSELTURK, 2010);

- P6: Há grande quantidade de acessos ao fórum após seu encerramento, como recurso de consulta; 
- P7: Não há picos de envio de mensagens, há homogeneidade de postagem durante todo o período do fórum;

- P8: Há relação entre a turma a qual o aluno pertence e a qualidade de sua participação no fórum.

A descrição dos procedimentos utilizados para a coleta e análise dos dados é apresentada a seguir.

\subsection{Coleta e análise dos dados}

O estudo foi realizado em uma disciplina semipresencial de Estatística Aplicada à Administração da FEA-RP/USP. Esta disciplina é oferecida no terceiro semestre do curso de graduação em Administração de Empresas, que tem duração de oito semestres para a turma diurna e dez semestres para a turma noturna. A disciplina possui quatro créditos (30 aulas no semestre) e foi oferecida na modalidade semipresencial nas turmas do período diurno e noturno, totalizando 99 alunos. Sendo uma disciplina semipresencial, foram incluídas atividades a distância que completaram 20\% da carga horária total. Dentre essas atividades foram realizadas sessões síncronas via chat, fórum de discussão, trabalhos em grupo e desenvolvimento de exercícios. As atividades presenciais compreenderam aulas teóricas e provas presenciais. Como os conteúdos foram os mesmos para ambas as turmas, as interações no fórum foram realizadas conjuntamente, ou seja, os alunos dos dois períodos desenvolveram as discussões no fórum conjuntamente.

O fórum teve como objetivo promover uma discussão crítica a respeito de um artigo acadêmico da área de Administração publicado em periódico, selecionado pela professora da disciplina, que utilizou a técnica estatística Análise de Variância (ANOVA) - um dos temas da matéria - para análise dos dados. O fórum teve como objetivos promover aprofundamento teórico sobre a técnica e aproximar teoria e prática, exemplificando o uso da ferramenta em um contexto real da Administração. $O$ artigo selecionado apresentava alguns problemas em relação à aplicação da técnica, o que daria múltiplas facetas à discussão e traria ao contexto questões mais sofisticadas a respeito do uso da Análise de Variância.

A atribuição de notas do fórum foi comparativa, de modo que os alunos que postassem maior quantidade de mensagens, consideradas adequadas, receberiam a melhor nota. Estipulouse um mínimo de duas mensagens por aluno e houve moderação diária de uma tutora, responsável por incentivar os alunos, inserir questões de alto nível, responder aos questionamentos e realizar o encerramento da discussão.

Como técnica de coleta de dados, foram utilizados os registros das discussões armazenados pelo ambiente virtual de aprendizagem. Os registros das discussões foram analisados por meio de análise de conteúdo e estatísticas descritivas. Os códigos são apresentados no Quadro 1.

\begin{tabular}{|c|c|c|}
\hline \multicolumn{2}{|c|}{ Tipo de código } & Significado do código \\
\hline \multicolumn{3}{|r|}{ Quantidade } \\
\hline \multicolumn{2}{|l|}{ A } & Observação ou opinião \\
\hline \multicolumn{2}{|l|}{ B } & Concordância com mensagem de outro participante \\
\hline \multicolumn{2}{|l|}{$\mathrm{C}$} & Exemplos para corroborar argumentos apresentados \\
\hline \multicolumn{2}{|l|}{$\mathrm{D}$} & Pergunta ou resposta para esclarecer alguma mensagem postada \\
\hline \multicolumn{2}{|l|}{$\mathrm{E}$} & Discordância com mensagens postadas \\
\hline \multirow{3}{*}{ Relevância } & & Qualidade \\
\hline & $\mathrm{R}(+)$ & Mensagem relevante ao assunto discutido \\
\hline & $\mathrm{R}(-)$ & Mensagem irrelevante à discussão \\
\hline
\end{tabular}




\begin{tabular}{|c|c|c|}
\hline \multicolumn{2}{|c|}{ Tipo de código } & Significado do código \\
\hline \multirow[t]{2}{*}{ Novidade } & $N(+)$ & $\begin{array}{l}\text { Proporciona novas informações e ideias que não haviam sido mencionadas ante- } \\
\text { riormente }\end{array}$ \\
\hline & $N(-)$ & Repetição do que já tinha sido postado sem acrescentar nada novo \\
\hline \multirow{2}{*}{$\begin{array}{l}\text { Correção ou } \\
\text { Adequação }\end{array}$} & $C(+)$ & Mensagem correta em termos teóricos \\
\hline & $C(-)$ & Mensagem incorreta em termos teóricos \\
\hline
\end{tabular}

Quadro 1. Codificação das mensagens do fórum

Fonte: Elaborado pelas autoras a partir do estudo de Yang, Newby e Bill (2005).

Após a classificação das mensagens dentro das categorias anteriormente expostas, aplicou-se uma análise de correspondência múltipla com objetivo de se relacionar as turmas (diurno e noturno) e seu desempenho no fórum, medido em termos de qualidade das mensagens postadas. Os resultados do caso investigado são apresentados a seguir.

\section{APRESENTAÇÃO E ANÁLISE DOS RESULTADOS DA PESQUISA}

Este capítulo apresenta a análise dos resultados desta pesquisa. Inicialmente, o perfil dos alunos que compuseram as turmas diurna e noturna é brevemente apresentado. A seguir, apresenta-se a análise da participação dos alunos nas discussões via fórum. Por fim, as proposições do estudo são retomadas, avaliando-se sua confirmação ou rejeição.

\subsection{Perfil da turma}

Participaram do estudo 99 alunos do curso de Administração, sendo $58 \%$ do período diurno e $42 \%$ do período noturno. A média etária é de 19,9 anos, havendo maior frequência do gênero masculino (66\%). A maior parte dos alunos possuía computadores próprios com acesso à Internet, sendo a conexão banda larga utilizada com maior frequência. Esses dados sugerem que os estudantes possuíam estrutura mínima apropriada para o bom desempenho das atividades.

A maioria dos estudantes nunca havia participado de um curso com atividades a distância. Apenas $5,3 \%$ dos alunos do período diurno e $16,7 \%$ do período noturno declararam ter esta experiência. Porém, consideravam que a utilização da Educação a Distância seria um agregador de valor à disciplina de Estatística.

\subsection{Análise do fórum}

O fórum teve como objetivo debater criticamente sobre um artigo acadêmico publicado em periódico, o qual utilizou a técnica análise de variância (ANOVA) para análise de dados. A ANOVA é uma técnica estatística de dependência muito utilizada na área de negócios para verificar a existência de diferença significante de médias entre grupos de uma variável dependente. Nesta atividade os alunos precisavam ler o artigo indicado e analisá-lo, baseando-se em instruções oferecidas pela professora e nos conhecimentos prévios adquiridos nas aulas teóricas, nos trabalhos práticos e nas leituras realizadas. Com base na leitura crítica, deveriam discutir com os colegas no fórum os pontos fortes e fracos do artigo, colocando-se na posição do avaliador de um periódico ou de um diretor de empresa, na atividade de avaliação de um relatório.

Embora seja uma técnica amplamente utilizada, a ANOVA, é frequentemente aplicada inadequadamente no contexto de negócios. Isto se deve ao fato de que seu uso adequado exige que alguns pressupostos (normalidade, homocedasticidade de variância, escala métrica das va- 
riáveis independentes etc.) sejam estritamente respeitados, o que nem sempre é observado em estudos desenvolvidos nesta área. Essas características oferecem diversos tópicos possíveis para discussão de um artigo que tenha aplicado esta ferramenta.

Para tanto, colocaram-se como regras para a participação dos alunos no fórum, o registro de no mínimo duas mensagens obrigatórias, e a atribuição das notas foi comparativa, pela quantidade e adequação de mensagens. Este fórum ficou ativo para postagem de mensagens por quinze dias. Após este período, permaneceu aberto por mais alguns dias como fonte de consulta, sendo posteriormente encerrado.

Observou-se que houve 254 mensagens postadas, as quais, para a realização deste estudo, foram classificadas nas categorias estabelecidas: observação, concordância, exemplos, pergunta/resposta, discordância (Quadro 2). As mensagens de observação continham uma opinião crítica a respeito da aplicação da ANOVA no artigo. As mensagens de concordância continham argumentação que corroborava com mensagens de observação anteriormente postadas. As mensagens de exemplos ilustravam algum argumento postado em outra mensagem. As mensagens denominadas perguntas/respostas continham perguntas e respostas acerca da ferramenta ANOVA. Já as mensagens de discordância apresentavam argumentação contrariando uma mensagem de observação. $O$ Quadro 2 evidencia a quantidade de mensagens postadas no fórum, separadas por participante, e classificadas conforme as categorias de análise estabelecidas para a realização desta pesquisa.

\begin{tabular}{|c|c|c|c|c|c|c|}
\hline Categorias & \multicolumn{2}{|l|}{ Diurno } & \multicolumn{2}{|l|}{ Noturno } & \multicolumn{2}{|l|}{ Tutora } \\
\hline Observação & 24 mensagens & $18,6 \%$ & 28 mensagens & $29,2 \%$ & 2 mensagens & $6,9 \%$ \\
\hline Concordância & 23 mensagens & $17,8 \%$ & 13 mensagens & $13,5 \%$ & 1 mensagem & $3,4 \%$ \\
\hline Exemplos & 2 mensagens & $1,6 \%$ & 1 mensagem & $1 \%$ & 2 mensagens & $6,9 \%$ \\
\hline Pergunta/resposta & 74 mensagens & $57,4 \%$ & 52 mensagens & $54,2 \%$ & 21 mensagens & $72,5 \%$ \\
\hline Discordância & 6 mensagens & $4,6 \%$ & 2 mensagens & $2,1 \%$ & 3 mensagens & $10,3 \%$ \\
\hline Total & \multicolumn{2}{|c|}{129 mensagens } & \multicolumn{2}{|c|}{96 mensagens } & \multicolumn{2}{|c|}{29 mensagens } \\
\hline Índice geral de participação & \multicolumn{2}{|c|}{ 2,2 mensagens/aluno } & \multicolumn{2}{|c|}{ 2,2 mensagens/aluno } & & \\
\hline $\begin{array}{l}\text { Porcentagem de alunos que } \\
\text { participaram }\end{array}$ & \multicolumn{2}{|c|}{$85 \%$} & \multicolumn{2}{|c|}{$86 \%$} & & \\
\hline
\end{tabular}

Quadro 2. Quantidades de mensagens no fórum

Fonte: Dados processados

Observa-se uma maior concentração de mensagens na categoria perguntas/respostas, que se caracteriza por lançar e debater questionamentos a respeito de teoria, aplicações e interpretações de resultado da técnica ANOVA. Considerando-se que o fórum possui como objetivo promover reflexão e debates críticos, esperava-se que houvesse realmente maior número de mensagens na categoria perguntas/respostas. Nota-se que a maioria dos alunos participou da atividade ( $85 \%$ no período diurno e $86 \%$ no noturno), o que corrobora com os resultados obtidos por Balaji e Chakrabarti (2010). No entanto, pode-se verificar também a não participação da ordem de $15 \%$ dos alunos, o que pode sugerir falhas no planejamento da atividade, o que é convergente aos resultados encontrados por Batista e Gobara (2007). Possivelmente, caso a atividade tivesse sido optativa, o nível de participação teria sido menor, conforme sugerem os achados de Yuselturk (2010). Logo, torna-se oportuno aos docentes o monitoramento das atividades realizadas via fórum, a fim de se estimular a participação de todos os alunos nesta atividade.

Neste fórum esperava-se ainda uma análise do artigo sob o ponto de vista da aplicação da ANOVA, na qual caberia discutir como a ferramenta foi aplicada, resultados obtidos, qualidade geral do artigo e outras possíveis aplicações da ferramenta. Observou-se que $93,3 \%$ das mensagens formaram parte destes tópicos analíticos e apenas $6,7 \%$ delas abrangeram tópicos sobre uso 
do software SPSS (Statistical Package for Social Science), Microsoft Excel e formatação do artigo, considerados inconsistentes com a proposta da atividade.

Em relação à qualidade das mensagens, elas foram classificadas de acordo com sua: adequação (se a mensagem era coerente com o tema proposto e com o tipo de discussão planejado), relevância (mesmo que a mensagem fosse coerente, ela poderia ter contribuição relevante para o desenvolvimento do pensamento crítico ou apenas apresentar uma afirmação que agregasse pouco para o desenvolvimento da discussão), correção (uma mensagem pode conter afirmações e argumentos equivocados, o que pode levar a conclusões equivocadas e impedir que se alcancem os objetivos pedagógicos propostos pela interação assíncrona), e repetição (uma mensagem pode trazer um argumento inédito à discussão ou algo anteriormente exposto por outro aluno). O Quadro 3 evidencia os resultados desta análise.

\begin{tabular}{|c|c|c|c|c|}
\hline Qualidade das mensagens & \multicolumn{2}{|c|}{ Diurno } & \multicolumn{2}{|c|}{ Noturno } \\
\hline Tópico Adequado & 124 mensagens & $94,5 \%$ & 96 mensagens & $95,9 \%$ \\
\hline Tópico Inadequado & 5 mensagens & $5,5 \%$ & 4 mensagens & $4,1 \%$ \\
\hline Mensagem Relevante & 115 mensagens & $89,1 \%$ & 88 mensagens & $91,7 \%$ \\
\hline Mensagem Irrelevante & 14 mensagens & $10,9 \%$ & 8 mensagens & $8,3 \%$ \\
\hline Mensagem Correta & 111 mensagens & $86 \%$ & 81 mensagens & $84,4 \%$ \\
\hline Mensagem Incorreta & 18 mensagens & $14 \%$ & 15 mensagens & $15,6 \%$ \\
\hline Mensagem Nova & 72 mensagens & $55,8 \%$ & 40 mensagens & $41,7 \%$ \\
\hline Mensagem Repetida & 57 mensagens & $44,2 \%$ & 56 mensagens & $58,3 \%$ \\
\hline $\begin{array}{l}\text { Mensagens em tópicos adequados, } \\
\text { relevantes, corretas e novas }\end{array}$ & 61 mensagens & $\begin{array}{l}47 \% \text { do } \\
\text { diurno }\end{array}$ & 35 mensagens & $\begin{array}{l}36 \% \text { do } \\
\text { noturno }\end{array}$ \\
\hline
\end{tabular}

Quadro 3. Qualidade das mensagens no fórum

Fonte: Dados processados

Observa-se a partir dos resultados apresentados no Quadro 3 que a maioria das mensagens foi considerada relevante para a discussão e correta ou pertinente. Entretanto, boa parte das mensagens foi repetida. Isto pode ser explicado pela obrigatoriedade de duas mensagens por aluno, notas comparativas e grande quantidade de participantes, tendo em vista que os alunos do período diurno e noturno participaram conjuntamente da discussão.

Foram observados picos de acesso nos últimos dias disponíveis para postagem de mensagens. Isto indica que o aluno engajou-se mais com a atividade próximo de seu encerramento, o que pode ser explicado pelo fato de a interação no fórum ter sido uma atividade avaliativa, o que corrobora os resultados obtidos por Balaji e Chakrabarti (2010). Adicionalmente, notouse um declínio acentuado nos acessos após o último dia de postagem, ou seja, poucos alunos acessaram o fórum posteriormente para consulta, o que também se deve à obrigatoriedade de participação. Esse resultado contraria os achados de Balaji e Chakrabarti (2010), pois indica que a interação ocorreu para garantir o desempenho na disciplina e não devido ao desenvolvimento de sinergias e comunidades.

Tendo em vista que no caso exposto o objetivo do fórum foi de aproximar a teoria da ANOVA ao uso real dessa técnica no cotidiano do administrador, habilitando os alunos a realizar uma análise crítica dessa aplicação, as instrutoras tornaram a atividade obrigatória e avaliativa, o que fez com que a meta de duas mensagens por aluno fosse alcançada (ao todo houve 224 men- 
sagens, ou seja, em média 2,3 mensagens por aluno). Entretanto, o estudo de Yuselturk (2010) que utilizou uma abordagem optativa, obteve média maior de mensagens postadas, embora tenha conseguido menor quantidade de alunos engajados na atividade.

Este contraponto sugere que a obrigatoriedade tem forte influência na participação. Porém, a qualidade da discussão e, por conseguinte, o desenvolvimento do raciocínio crítico e a internalização dos conteúdos da Estatística dependem da atuação da tutoria e da forma como o aluno é trazido a participar desse desenvolvimento coletivo do conhecimento. Assim, uma avaliação diferenciada que levasse o aluno a engajar-se na discussão no fórum desde a data de início da atividade e uma abordagem mais ativa da moderação poderiam surtir impactos positivos nos resultados, tais como redução das mensagens repetidas e melhor distribuição dos acessos dos alunos durante todo o período da atividade.

Analisando-se o último dia da atividade, tem-se uma grande porcentagem de mensagens relevantes e corretas. Entretanto, apenas 33\% delas foram consideradas novas, ou seja, houve grande repetição. Isto sugere que os alunos efetuaram sua participação na atividade somente no último dia, quando muitas ideias já haviam sido apresentadas, como se pode verificar no Quadro 4.

\begin{tabular}{|c|c|c|c|c|}
\hline Mensagens no último dia & \multicolumn{2}{|c|}{ Diurno } & \multicolumn{2}{c|}{ Noturno } \\
\hline Relevantes & 34 mensagens & $79 \%$ & 50 mensagens & $91 \%$ \\
\hline Corretas & 34 mensagens & $79 \%$ & 43 mensagens & $78 \%$ \\
\hline Novas & 14 mensagens & $33 \%$ & 18 mensagens & $33 \%$ \\
\hline
\end{tabular}

Quadro 4. Estatísticas das mensagens no último dia do fórum

Fonte: Dados processados

Este achado também sugere que a obrigatoriedade levou à interação e não à construção de comunidades conforme sugere o estudo de Balaji e Chakrabarti (2010). Outras razões para isso podem ser a dificuldade em se encontrar um tópico para a discussão dado a complexidade do assunto, a participação de muitos alunos concomitantemente e o tempo necessário para se desempenhar adequadamente uma interação no fórum, como sugere o estudo de Kear et al. (2010).

$\mathrm{Na}$ última etapa da pesquisa, realizou-se uma análise de correspondência múltipla com objetivo de verificar a existência de relação entre as turmas (diurno e noturno) e as variáveis de classificação das mensagens do fórum. Desta forma, é possível verificar se há diferença entre o padrão de mensagens postadas pelas duas turmas. Para esta análise foram utilizadas as variáveis: classe das mensagens, relevância, novidade, adequação ou correção e as turmas (diurno e noturno). O teste Qui-quadrado, requisito para aplicação da técnica, ao nível de significância de $1 \%$ não rejeita a hipótese nula ( $p$-valor>1\%) - H0: cada variável de classificação das mensagens no fórum é independente da variável turma.

Este resultado indica que a qualidade de participação no fórum não possui relação com a turma a qual o aluno pertence. Isto é coerente com os achados de Batista e Gobara (2007) e Murphy et al. (2011). Os baixos valores do coeficiente de contingência, que mensura a força da relação entre as variáveis, no Quadro 5, reforçam a independência entre as variáveis verificada pelo teste Qui-quadrado.

\begin{tabular}{|c|c|}
\hline Variáveis & Coeficiente de contingência \\
\hline Classe de mensagens versus Turma & 0,14 \\
\hline Relevância versus Turma & 0,042 \\
\hline Correção/adequação versus Turma & 0,023 \\
\hline Novidade versus Turma & 0,139 \\
\hline
\end{tabular}

Quadro 5. Coeficientes de contingência

Fonte: Dados processados 
Entretanto, mesmo com a não rejeição da hipótese de independência, efetuou-se a análise de correspondência múltipla, obtendo-se o mapa apresentado na Figura 1, para uma análise exploratória em relação ao posicionamento das turmas em relação à classificação das mensagens.

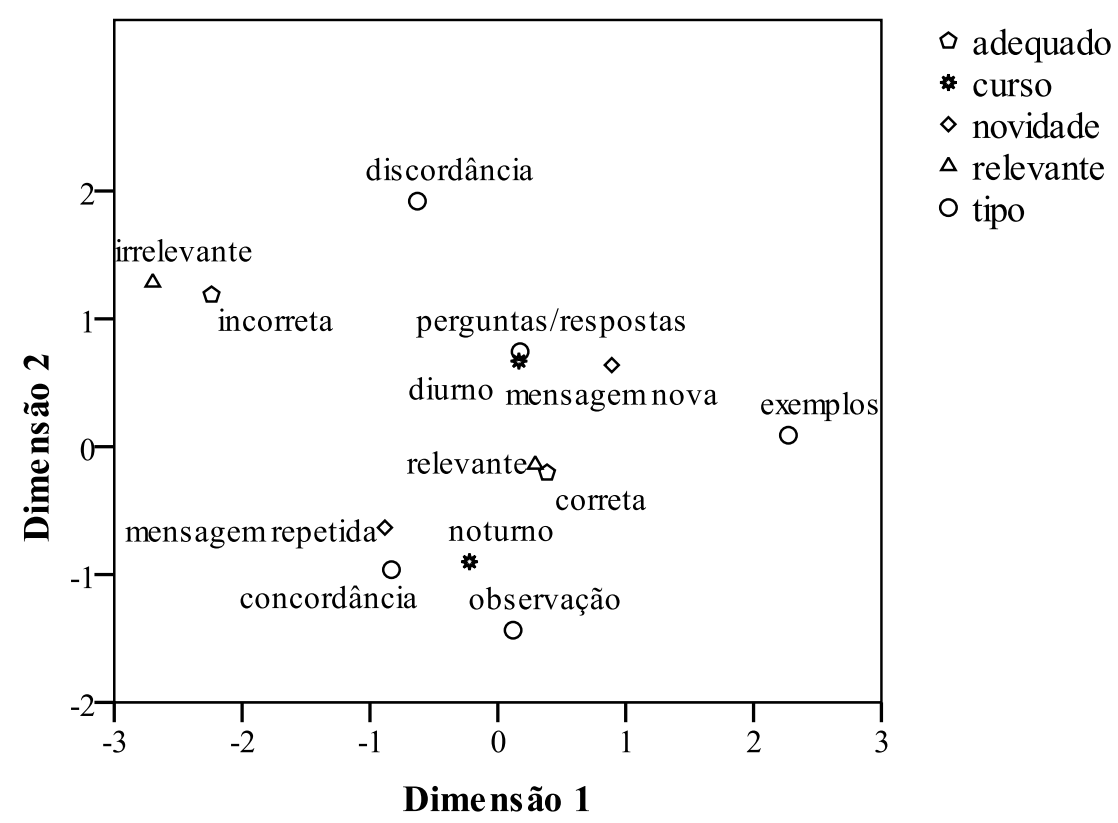

Figura 1. Mapa obtido pela análise de correspondência Fonte: Dados processados

A Figura 1 mostra que a turma do período diurno possui maior proximidade com as mensagens de perguntas e respostas (caracterizadoras de debate) e mensagens novas, ao passo que a turma do período noturno possui maior proximidade com as mensagens de concordância e observação e com as mensagens repetidas. Ambas as turmas possuem distâncias similares das mensagens relevantes e corretas e ambas estão distantes das mensagens incorretas e irrelevantes.

Assim, ambas as turmas possuem padrões diferentes de participação no fórum. A turma do período diurno apresentou maior frequência de mensagens novas e que caracterizam debate, o que corrobora os objetivos da atividade. Por outro lado, a turma do noturno apresentou maior frequência de mensagens repetidas e contribuiu, em maior frequência que o diurno, com apontamentos do tipo observação, que não caracterizam debates. Portanto, o período diurno teve participação mais adequada no fórum nesses aspectos. No que se refere à relevância e pertinência das mensagens, ambos os grupos possuíram desempenhos próximos e adequados.

As turmas tiveram os mesmos conteúdos teóricos durantes as aulas, o mesmo atendimento da tutoria e os mesmos materiais didáticos disponibilizados; porém, observa-se diferença entre seu desempenho no fórum. Isto pode estar relacionado à própria natureza do curso noturno, no qual os estudantes, em maioria, trabalham em período integral, enquanto no curso diurno, por ser integral, os alunos possuem maior disponibilidade para dedicar-se às atividades acadêmicas. Nesse sentido, dado que a discussão no fórum é uma atividade complexa que exige leitura prévia de material, pesquisa, acompanhamento constante da discussão (BALAJl; CHAKRABARTI, 2010) e, portanto, grande dedicação de tempo, a maior disponibilidade do diurno pode explicar sua melhor participação. 
Após a conclusão do fórum foi desenvolvido um trabalho prático, no qual os estudantes deveriam propor uma situação-problema na qual seria possível a aplicação da ANOVA, simular os dados, aplicar a técnica e analisar os resultados. Observou-se que, em média, os alunos do período diurno tiveram maiores notas nesse trabalho (nota média $=8,1$; desvio-padrão $=1,2$; coeficiente de variação= $15 \%$ ) que os alunos do período noturno (nota média= 7,2; desvio-padrão=1,4; coeficiente de variação=19\%). Desta maneira, é possível que a discussão no fórum tenha efetivamente contribuído para a aprendizagem da técnica, pois ambos os grupos tiveram desempenhos satisfatórios no trabalho. Além disso, a ligeira superioridade do desempenho da turma do período diurno pode ser decorrente do seu maior envolvimento nas atividades do fórum.

\subsection{Análise das proposições do estudo}

Com base na análise dos resultados pôde-se verificar que algumas das proposições do estudo foram confirmadas conforme apresentado no Quadro 6.

\begin{tabular}{|c|c|}
\hline Proposições & Resultado \\
\hline $\begin{array}{l}\text { P1: Há predominância de mensagens que } \\
\text { caracterizam discussões aprofundadas } \\
\text { (debates). }\end{array}$ & $\begin{array}{l}\text { Confirmada. Houve realmente predominância das discussões } \\
\text { em profundidade. }\end{array}$ \\
\hline $\begin{array}{l}\text { P2: As mensagens são predominantemen- } \\
\text { te relevantes ao assunto discutido. }\end{array}$ & $\begin{array}{l}\text { Confirmada. Houve maior frequência de mensagens relevan- } \\
\text { tes em relação às irrelevantes. }\end{array}$ \\
\hline $\begin{array}{l}\text { P3: As mensagens, em maioria, apresen- } \\
\text { tam ideias novas que não haviam sido an- } \\
\text { teriormente expostas na discussão. }\end{array}$ & $\begin{array}{l}\text { Não confirmada. Houve proporções similares de mensagens } \\
\text { novas e repetidas }\end{array}$ \\
\hline $\begin{array}{l}\text { P4: As mensagens, em maioria, são consi- } \\
\text { deradas corretas em termos teóricos. }\end{array}$ & Confirmada. Houve predominância de mensagens corretas. \\
\hline $\begin{array}{l}\text { P5: Há participação da maioria dos alunos, } \\
\text { devido à obrigatoriedade da atividade. }\end{array}$ & $\begin{array}{l}\text { Confirmada. Houve participação da maioria dos alunos no } \\
\text { fórum. Isto se deve provavelmente à obrigatoriedade da ati- } \\
\text { vidade e ao seu peso no cálculo da média final do aluno. }\end{array}$ \\
\hline $\begin{array}{l}\text { P6: Há grande quantidade de acessos ao } \\
\text { fórum após seu encerramento como re- } \\
\text { curso de consulta }\end{array}$ & $\begin{array}{l}\text { Não Confirmada. Houve declínio acentuado dos acessos após } \\
\text { o encerramento do prazo para postagem de mensagens. }\end{array}$ \\
\hline $\begin{array}{l}\text { P7: Não há picos de envio de mensagens, } \\
\text { há homogeneidade de postagem durante } \\
\text { todo o período do fórum. }\end{array}$ & $\begin{array}{l}\text { Não confirmada. Constataram-se picos de envio de mensa- } \\
\text { gens no último dia da atividade, nas últimas horas em que a } \\
\text { postagem estaria disponível. }\end{array}$ \\
\hline $\begin{array}{l}\text { P8: Há relação entre a qualidade de parti- } \\
\text { cipação no fórum e a turma à qual o aluno } \\
\text { pertence. }\end{array}$ & $\begin{array}{l}\text { Não confirmada. O teste qui-quadrado não rejeitou a hipóte- } \\
\text { se nula, o que indica independência entre a classificação das } \\
\text { mensagens postadas no fórum e a turma. Porém, apesar de } \\
\text { a relação não significativa, o mapa ilustra que os alunos do } \\
\text { período diurno tiveram participação mais adequada que os } \\
\text { alunos do período noturno em relação à classe das mensa- } \\
\text { gens e à novidade. }\end{array}$ \\
\hline
\end{tabular}

Quadro 6. Análise das proposições do estudo

Fonte: Das autoras com base nos resultados do estudo

Observou-se que a maioria dos estudantes matriculados na disciplina estudada participou da discussão proposta no fórum. Dado a complexidade da atividade, a obrigatoriedade pode ter sido um dos fatores determinantes da alta participação.

De forma geral, o objetivo do fórum foi atingido, pois houve predominância das mensagens de debate, corretas e relevantes ao propósito da discussão, o que indica que o objetivo de tornar o ensino de Estatística mais próximo da realidade do administrador foi alcançado, conforme sugerem os estudos de Gould (2010) e Zieffler et al. (2012). Todavia, houve grande repetição, ou seja, as mensagens, embora adequadas, tratavam de assuntos já discutidos anteriormente 
por outros colegas. Isto se deve à grande quantidade de alunos (totalizando 99 alunos nas duas turmas), às duas mensagens obrigatórias e ao fato de grande parte das mensagens terem sido postadas próximas do prazo final, o que pode ser explicado pela obrigatoriedade de participação.

O material produzido na discussão não foi acessado pelos participantes após o final da discussão como fonte de consulta, conforme se havia planejado no desenho da atividade. Por fim, esperava-se que ambas as turmas tivessem padrões de participação similares, contribuindo com mensagens profundas, corretas, relevantes e novas, já que tiveram exatamente o mesmo conteúdo teórico ministrado. No entanto, observou-se que o período diurno teve melhor participação com relação à profundidade das mensagens e à novidade que o período noturno.

\section{CONCLUSÕES}

A inserção de disciplinas de Estatística nos cursos de graduação em administração busca desenvolver a capacidade de análise crítica dos administradores egressos deste curso, em temas relacionados a esta área do conhecimento. $O$ fórum é uma ferramenta que estimula a cognição do aluno incentivando sua participação em atividades extraclasse (ALAVI; TAGHIZADEH, 2013). Neste contexto, o objetivo de se "avaliar o uso da ferramenta fórum no ensino de Estatística Aplicada à Administração" foi alcançado por meio da realização de um estudo de caso, cujo objeto foi um fórum efetuado em um curso de graduação em Administração de Empresas.

A utilização de uma ferramenta assíncrona para discussão e análise de um artigo contribui para a aproximação entre a teoria estatística e a prática. Esta modalidade de discussão é adequada a esse propósito, pois permite que alunos e tutor planejem sua participação e a efetuem no momento que lhes for mais conveniente. Nesse sentido a discussão é mais rica do que presencialmente, pois todos os estudantes são compulsoriamente convidados a participar e possuem regras claras e objetivas para interação, o que torna o processo mais dinâmico. No que se refere ao professor, torna-se a avaliação menos complexa, pois as discussões permanecem registradas no banco de dados e, com base nas regras estabelecidas, torna-se relativamente simples atribuir nota aos estudantes.

O fórum estudado foi desenhado para que a teoria e aplicações da análise de variância fossem discutidas em profundidade. Observou-se que a atividade atingiu seu objetivo, à medida que a maioria dos estudantes participou da discussão e houve predomínio de mensagens corretas e relevantes que caracterizavam debates. No entanto, alguns pontos não corroboram os objetivos propostos para o fórum: repetição de assuntos, baixa taxa de acesso após o encerramento da discussão, picos de mensagens no último dia da atividade e padrão de participação relativamente distinto entre as turmas do período diurno e noturno.

Essas dificuldades, sob o ponto de vista da educação a distância, sugerem que a obrigatoriedade cumpre seu papel ao fazer com que a maioria dos alunos participe da discussão. Por outro lado, os problemas expostos anteriormente sugerem que alguns alunos participaram da atividade apenas por seu caráter compulsório e possivelmente não extraíram desse debate os resultados esperados pelos instrutores, o que acarreta uma limitação. Esses resultados são coerentes com aqueles encontrados por outros pesquisadores em contextos diversos e indicam a necessidade de revisão do design dessa atividade, Batista e Gobara (2007), Yuselturk (2010), Balaji e Chackrabarti (2010), Kear et al. (2010), Murphy et al. (2011).

Sob o ponto de vista do ensino de Estatística para não estatísticos, observou-se que a discussão assíncrona tem potencial para tornar o processo educacional dessa disciplina mais autêntico e autônomo, como sugerem Gould (2010) e Zieffler (2012), em específico o ensino de Administração (CORDEIRO; SILVA, 2012). 
A utilização do fórum cumpriu seu papel e mostra-se como uma ferramenta valiosa no ensino de estatística, pois permite discussões para aprofundamento teórico e aproximação entre teoria e prática. Assim, têm-se como contribuição do estudo algumas diretrizes para o uso do fórum no contexto educacional, em especial no ensino de disciplinas exatas, como é o caso da Estatística Aplicada. Porém, para seu sucesso, é necessário o planejamento prévio cuidadoso e a antecipação de possíveis desvios, tais como baixa participação, mensagens inadequadas, repetição, etc., formulando-se ações que estimulem efetivamente o envolvimento do estudante e sua participação nestas atividades de ensino.

Os achados da pesquisa permitem concluir que, utilizado de maneira adequada, o fórum pode ser uma eficiente ferramenta de ensino, contribuindo para o desenvolvimento do raciocínio crítico, da articulação de ideias e da argumentação reflexiva e estruturada. Dessa forma, o processo de ensino-aprendizagem deixa de ser passivo, torna-se iminente a responsabilidade do aluno em sua aprendizagem e o professor assume o papel de facilitador, deixando de ser o centro do processo.

Como limitação do estudo destaca-se que a análise considerou apenas uma interação em fórum em duas turmas de um curso de graduação, o que oferece insights interessantes a respeito da temática, estimulando a realização de novos estudos. No entanto, não se pode tecer comentários conclusivos e nem generalizadores sobre a real influência desta ferramenta no ensino de estatística em diferentes cursos, cabendo a replicação do estudo a outras turmas deste e de outros cursos, inclusive em outras instituições de ensino, para que se possa obter maior conhecimento sob este tema.

\section{REFERÊNCIAS}

ALAVI; S.M.; TAGHIZADEH, M. Cognitive presence in a virtual learning community: an EFL case. Journal of Distance Education, v.27, n.1, p.8-13, 2013.

ANDRESEN, M.A. Asynchronous discussion forums: success factors, outcomes, assessments, and limitations. Educational Technology \& Society, v. 12, n. 1, p.249-257, 2009.

BALAJI, M. S.; CHAKRABARTI, D. Student Interactions in Online Discussion Forum: Empirical Research from "Media Richness Theory " Perspective. Journal of Interactive Online Learning, v. 9, n. 1, p. 1-22, 2010.

BATISTA, E. M.; GOBARA, S. T. O fórum online e a interação em um curso a distância. Revista Novas Tecnologias na Educação, v. 5, p. 1-10, 2007. Disponível em: <http://www.cinted. ufrgs.br/renote/jul2007/artigos/8cErlinda. pdf2007>. Acesso em:05 set. 2013.

BEUCHOT, A.; BULLEN, M. Interaction and interpersonality in online discussion forums. Distance Education, London, v. 26, n. 1, p. 6787, maio. 2005.

CORDEIRO, R. A.; SILVA, A. B. DA. Os estilos de aprendizagem influenciam o desempenho acadêmico dos estudantes de finanças? Revista de Administração da UFSM, v. 5, n. 2, p. 243-261, 23 ago 2012.

FREITAS, A. S. de; BERTRAND, H. Ensino a distância no Brasil: avaliação de uma parceria universidade-empresa. In: EnANPAD, 30., 2006, Salvador. Anais... Salvador: Associação Nacional de Pós-Graduação e Pesquisa em Administração, 2006.

GARRISON, D. R.; CLEVELAND-INNES. Facilitating cognitive presence in online learning: interaction is not enough. The American Journal of Distance Education, Mahwah, v.19, n.3, p. 133-148, 2005.

GIL, A.C. Como elaborar projetos de pesquisa. 4 ed. São Paulo: Atlas, 2002. 175p.

GIULIANI, A. C. Perfil Profissiográfico dos Egressos do Programa de Mestrado Profissional 
em Administração de uma Instituição de Ensino do Interior do Estado de São Paulo. Revista de Administração da UFSM, v. 3, n. 1, p. 94-108, 2010.

GOULD, R. Statistics and the Modern Student. International Statistical Review. v., n.2, p. 297315, 2010.

KEAR, K.; WOODTHORPE, J.; ROBERTSON, S.; HUTCHISON, M. From forums to wikis: Perspectives on tools for collaboration. The Internet and Higher Education, v. 13, n. 4, p. 218-225, dez 2010.

KEEGAN, D. Foundations of Distance Education. $3^{\text {rd }}$. New York: Routledge, 1996, 224 p.

LAAT, M. D.; LALLY, V. It's not so easy: researching the complexity of emergent participant roles and awareness in asynchronous networked learning discussions. Journal of Computer Assisted Learning, Osney Mead, v. 20, p. 165171, 2004.

LI, Y.; DONG, M.; HUANG, R. Toward a semantic forum for active collaborative learning. Educational Technology \& Society, v.12, n.4, p.71-86, 2009.

MABRITO, M. A study of synchronous versus asynchronous collaboration in na online business writing class. The American Journal of Distance Education, Mahwah, v. 20, n. 2, p. 93-107, 2006.

MOORE, M.G.; KEARSLEY, G. Educação a distância: uma visão integrada. São Paulo: Cengage Learning, 2008. 398p.

MURPHY, E.; RODRÍGUEZ-MANZANARES, M. A.; BARBOUR, M. Asynchronous and synchronous online teaching: Perspectives of Canadian high school distance education teachers. British Journal of Educational Technology, v. 42, n. 4, p. 583-591, 13 jul 2011.

NIESS, M.; GILLOW-WILES, H. Developing asynchronous online courses: key instructional strategies in a social metacognitive constructivist learning trajectory. Journal of Distance Education, v.27, n.1, p.1-7, 2013.

NOLAN, D.; SPEED, T. P. Teaching statistics theory through applications. The American Statistician, Alexandria, v. 53, 4, p. 370-375, nov. 1999.

PAN, W.S. The challenges of teaching statistics in the current techonology environment. Journal of American Academy of Business, Cambridge, v. 3, p. 351-355, set. 2003.

TEMPELAAR, D. T.; RIENTIES, B.; LOEFF, S. S. VAN DER; GIESBERS, B. INTRODUCTORY STATISTICS TO A STRONG DIVERSITY OF STUDENTS: 8th. ICOTS. Anais... Ljubljana: International Association for Statistical Education. , 2010.

VARGAS, K. S.; BIRRER, J. A.; MINELLO, I. F. Estilos de aprendizagem e níveis de comprometimento organizacional: uma abordagem com residentes multiprofissionais da saúde. Revista de Administração da UFSM, v. 5, n. 3, p. 589-606, 2012.

VOLERY, T. Online Education: An Exploratory Study into Success Factors. Journal of Educational Computing Research, v. 24, n. 1, p. 77-92, 1 mar 2001.

YANG, Y. T. C.; NEWBY, T. J.; BILL, R. L. Using Socratic questioning to promote critical thinking skills through asynchronous discussion forums in distance learning environments. The American Journal of Distance Education, Mahawah, v. 19, n. 3, p. 163-181, 2005.

YIN, R.K. Estudo de caso: planejamento e métodos. 3. ed. Porto Alegre: Bookman, 2005. $212 \mathrm{p}$.

YUSELTURK, E. An investigation of factors affecting student participation level in an online discussion forum. The Turkish Online Journal of Educational Technology, v. 9, n. 2, p. 24-32, 2010.

ZIEFFLER, A.; PARK, J.; GARFIELD, J.; DELMAS, R.; BJORNSDOTTIR, A. The Statistics Teaching 
FÓRUM DE DISCUSSÃO COMO FERRAMENTA NO ENSINO DE ADMINISTRAÇÃO: UM ESTUDO EM UMA DISCIPLINA DE ESTATÍSTICA APLICADA

Inventory: A Survey on Statistics Teachers ' Classroom Practices and Beliefs. The Teaching of Introductory Statistics At The College Level. Journal of Statistics Education, v. 20, n. 1, p. 1-29, 2012. 